\title{
Using Analog Models based in Physical Systems for
}

\section{Technology Management Processes}

\author{
Vega-González Luis Roberto \\ Correspondence: Vega-González Luis Roberto, Instituto de Ciencias Aplicadas y Tecnología, Universidad Nacional \\ Autónoma de México, Circuito Exterior S/N, Ciudad Universitaria, A.P. 70-186, Alcaldía Coyoacán, CP 04510, Ciudad \\ de México. Tels. Conmutador 5622-8602 ext. 1118 y 1117; Directo 5622-8617.
}

Received: November 4, 2020

Accepted: January 16, 2021

Online Published: January 25, 2021

doi:10.11114/bms.v7i1.5141

URL: https://doi.org/10.11114/bms.v7i1.5141

\begin{abstract}
The empirical management work done in research, development and innovation projects $(\mathrm{R} \& \mathrm{D}+\mathrm{I})$ conducted at the liaison and technology transfer office of a public Institute of the National Autonomous University of Mexico (UNAM, from Spanish), allowed us to identify discrete management processes. The objective of this work was to present some of these processes, through the elaboration of pragmatic analog models based in physical systems. Models presented can help students, novices and other professionals to understand the way in which these processes are carried out. This eventually will make their learning more efficient and improve the way in which they address the management problems. We conclude that by complementing the professional and individual empirical views with technical, organizational and societal perspectives, it is possible to obtain useful knowledge from building and developing analog models which represent reality. Finally, complementing the models with a good management theoretical dose will provide good technology management practitioners for all kind of institutions.
\end{abstract}

Keywords: project technology management, analog models, physical systems

\section{Introduction}

According to Aguilera (2013), scientific knowledge "is the fruit of objective living conditions, in which there are people, communities and organizations interested in working methodically with aspects of objective reality". The objective of formal and factual sciences is to contribute to, produce and offer scientific knowledge to humanity.

Scientists use the scientific method and many other research tools for inquiry, and for experimental procedures to learn about the world. Among the auxiliary tools they use to achieve their research objectives, are experience-based models. For Aguilar (op cit., page 87) there exists another tool to obtain knowledge from the real world:

"It relates to the production of empirical knowledge that originates not only in a part of reality, but also considering the experience of the knowing subject to work with facts or factual situations. In this case, the produced data strengthens the normative vision of the problem studied, and at the same time, produces evidence through rules and procedures that allow the capture of relevant information that then leads to the construction of arguments."

Therefore, practical or empirical knowledge can help others to understand how processes in different fields of knowledge run. This is particularly true for practitioners interested in the field of management of technology; a complex field, particularly as regards how research, development and innovation $(R \& D+I)$ projects occur. This is because in this field, there are many stakeholders, multidisciplinary teams, processes, variables, etc.

Thus, models serve as empirical heuristic resources with which we work segments of reality. Their main purpose is to make it possible for scientists to discover causal relationships. Aguilera (op cit., page 85)

Research or teaching processes usually focus on different fields of knowledge. In each field, the object of study is defined as precisely as possible. Sometimes, concepts that are difficult for the researchers, the teachers or the students to interpret are also presented.

To understand the phenomena associated with difficult problems and solve them, interested parties use different resources including making different types of models or representations. The most common resources used are intuitive, mental, 
conceptual, analog teaching, and theoretical models. All of these are the tools used by most researchers and different teaching communities.

Mental models serve as representations of thoughts of students, analysts and researchers. Although a conceptual model is derived from the reasoning model, the fundamental difference between the two is that the conceptual model will always be associated with a specific concept or theme whereas the reasoning model will not. On the other hand, an intuitive model is developed when there are no immediate references in our environment that allow us to establish a first approach to the notion of interest. (Belmonte and Sierra, 2011)

Theoretical models are those obtained by demonstrating hypotheses from deductive procedures using the scientific method. Theoretical models constitute the baggage of scientific knowledge relative to some field of knowledge. Scientific knowledge is characterized because it requires study, analysis and explanation of the facts that are defined as problems.

Despite theoretical models being very useful in the field of research, they do not always provide the best results for teaching. This is because as opposed to promoting the students' reasoning, these models focus on the quantification of the results of various problems through the use of numerical quantities of physical variables.

On the other hand, Godoy (2002) defines an analogy as saying that one thing is like the other. In other words, we can use elements, concepts, systems and mechanisms to explain electrical and biological phenomena, the functioning of human organs, the evolution of a country's economy and many other human, social or administrative processes. Due to this, didactic analog models are important teaching resources in any theoretical or empirical field because they favor the construction of mental images of the study subject and help with the conceptualization of the diverse themes (Zamorano, Gibss and Viau, 2006).

Models are extensively diffused in the field of physics and engineering teaching (Godoy, 2002; Bagnato and Rodrigues, 2006; Zamorano, op cit.). They have also been used to understand teaching problems in medicine (Sánchez y Luengas, 2011) up to a point that they have been converted to a teaching research line. Besides this, it is clear that both interdisciplinary scientific research and the practical technological development work could benefit from the building and use of analog models.

Hofstadter (2001) cited by Godoy (op cit.) states that analogies not only explain or solve problems, but are also the center of our cognitive system thereby making it possible for us to reason. For Hofstadter the analogy is "the engine of the thought car" and "the interstate highway of cognition" (Palmer, 2009).

The hypothesis of this work is to study and understand some management of technology processes, elaborating pragmatic analog models is essential to provide a foundation to a particular conception of our reality. In this work we will discuss the use of physical models to understand and solve cognitive problems in technology management, specifically as regards the inception to completion of $\mathrm{R} \& \mathrm{D}+\mathrm{I}$ projects.

\section{Theoretical Framework}

\subsection{Cognition and Analog Empirical Models}

The most accepted definition of cognition is the ability of living beings have to process information from perception, (which is the stimuli that come to us from the outside world through our senses), the knowledge acquired through experience and our subjective characteristics to integration of all this information to value and interpret the world. Cognition is also understood as the ability we have to assimilate and process data that comes to us from different pathways as perception, experience, language, memory and beliefs, to convert it into knowledge. (Mejía and Escobar, 2012).

Through cognition, individuals create cognitive maps to represent their perceptions of the world surrounding them. These cognitive maps are closely related to behavior that exists in an individual's family, organizations and the society he or she belongs to. (Zapata and Canet, 2009)

Within organizations' framework, Bettis and Prahalad (1995) cited in Zapata and Canet (op cit, pp. 240), explain that mental schemes allow managers to categorize events, evaluate their consequences and select the most suitable actions. This then becomes a product of the interpretations of their experiences. Undoubtedly, the construction of analogous empirical models depends on the mental schemes of persons who develop a specific knowledge field in practice at a particular time.

\subsection{Analog Models and Education}

Currently, analogous models in teaching sciences are used universally. (Fernández, Jiménez and González, 2003; Coll, France, and Taylor, 2005; Rengifo, Fariña de Lander, Cabrera de Reyes, 2009). This is possibly due to the contributions of one of the first transdisciplinary disciplines, cybernetics, as a general philosophy of technology founded by the American mathematician Norbert Wiener (1894-1964). (Siles, 2007). 
In 1942, Wiener in the company of Julian Bigelow and Arturo Rosenblueth, compared humans to machines. Wiener (1949) posited that under the cybernetic approach, machines and humans are analogous or equivalent in terms of behavior and information, but differ in their emergency and construction process.

After a comparative analysis, Wiener and his team concluded that all informational entities, be they biological, artificial or mechanical, can be defined by the nature of the information exchanges that they sustain with its environment. Thus, the purpose of cybernetics was to understand "information exchange behaviors".

From the philosophical point of view, Rolleri (2013) mentioned that some structuralism philosophers state that theories are hierarchical networks of different classes of models, whereas other philosophers maintain that models are relatively independent or autonomous from the theories.

Aduríz-Bravo (2012) presents the works of Chamizo (2006), that focuses on relevant characteristics of scientific and theoretical models that despite being developed from analog physical systems, they can still be recognized in all kinds of models like those used for organizational management and transdisciplinary models, among others.

The following are characteristics of models: they (1) are simple representations developed to understand objects, systems, phenomena or processes, (2) are tools to try to answer to scientific, organizational or technical questions and therefore are used to obtain information and facts on events to which we have no direct access, (3) link to the phenomena they represent by being likened to reality to some degree, and allow us to derive hypotheses that can be tested, (4) can be expanded, corrected and improved, (5) are developed throughout history, in an iterative review process to accommodate new empirical evidence, (6) must be accepted (agreed) by the scientific community or the one that corresponds according to the area of application, and (7) they can be classified into different types including those iconic as images and conceptual or scale models.

\subsection{General Systems Theory and Management Models}

General Systems Theory has (GST) been used in all knowledge fields including organizations management. (Peralta, 2016). It recognizes that the organization is a total system in which both its individual elements and their interrelationships are equally important since the actions of some of them affect either the behavior of others or the system as a whole.

GST uses models to analyze and comprehend organizations' management. By the last quarter of $20^{\text {th }}$ century, Kahn y Katz (1978) proposed that the organization is an open system related to an environment, to which the organization delivers products and from which the organization receives energy and feedback. Organizations can also be studied as adaptive and complex systems, regarded as open systems that possess the properties of emergence, self-organization and evolution. On a different note, Terrazas (2009) developed a financial management model based on causal relationships to build problem and objective trees.

In the field of industrial engineering research, Liévano and Villada (2013) formulated an inventories' model that was based on dynamic physical systems models which capture the complexities among the relationships between variables found in the inventories of firms that handle immense flow of merchandise and warehouses. This inventory's based model is based on causal relationships that capture the system's behavior and the variables feedback cycles. These causal variables absorb the process's non-linearity's and permit the calculation of product reorder points.

\subsection{Models in Organization Management}

In modern dynamic organizations long-term decision-making is a complex and conflicting nature process, managers and consultants therefore use a wide range of tools and techniques to support strategic decision-making in increasingly complex, competitive and dynamic business environments.

Emre and Önner, (2014) propose that currently, organization management must be systemic. Therefore, they considered using Integral Management Model (IMM) for the management of Information Technologies. An IMM has the following characteristics: it (a) is integrative and needs a comprehensive set of essential variables to be built, (b) considers management as a multidimensional process, (c) also considers management as a multilevel process by defining normative, strategic and operational levels on a horizontal pane, (d) is a recursive process according to the IMM, where a recursive structure is comprised of autonomous units within autonomous units and as a result, IMM can be applied to any level of recursion within an organization; and (e) all components of the IMM are dynamically inter-related.

Saritas and Oner (2004) basing their opinions on a systemic approach, consider IMM a useful way of developing longterm normative policies and strategies and their transformations into actions by taking into consideration necessary changes that occur in organizational structures and behaviors.

On the other hand, the goal of an effective technology management practitioner is to be able to develop an ability to understand and putt into operation different technology management actions needed in an organization to effectively create valuable products for the society. This way, the organization will help to create wealth and increase people's quality 
of life. In this sense, analog models are used as tools to understand the technology developing processes required for innovation will address the need for innovation and for managing change and uncertainty.

We ought to be acquainted of two important situations. Firstly, we need to acknowledge that all organizations face and have faced problems over time. However, today, technology management practitioners face more complex problems. One of the prime features of today's complex problems is that they quickly develop into system-wide problem. (Ackoff, 1974 cited by Saritas \& Oner op. cit). Conversely, the growth of a systems' complexity demands changes in management and decision-making capability.

To deal with this situation, Linstone (1984) stated that:

"Data and models comprise the basic building blocks of inquiry. Logic and rationality as well as objectivity are likewise presupposed. Order, structure, and quantification are sought wherever possible. Observation and model building, experimentation and analysis are usually aimed at improving predictive capability. Validation of hypotheses and replicability of observations and experiments are expected. The attainment of elegant models and best or optimal solutions is particularly prized."

In the center of his model, Linstone (op. cit) suggested the following interconnected perspectives:

1. T: the technical perspective,

2. O: the organizational and societal perspective, and

3. P: the personal and individual perspective.

These three perspectives in Linstone's model assume that problems in real-life situations are managed by: (1) analyzing alternatives, (2) making decisions about which alternative to choose, and (3) successfully implementing of the chosen alternative. (Saritas and Oner, op. cit. page 37)

\subsection{Physical Analog Models for Technology Management}

The first example of physical models used to understand technology management processes, the Eddie Obeng's model for innovation metrics, is presented in Figure 1.

In this model, a pipe flow fluid mechanics analogy is used to illustrate the rate of change that has been taking place in the world. Essentially, he illustrated that the rate of change changed from what can be described as a "laminar flow" regime, where change was quite slow and the interactions were fewer and further apart, to the current state that can be described as a "turbulent flow" regime, where the rate of change has outpaced the rate of learning. (Obeng, 2012, quoted by Radziszewski, 2020)

This implies that when someone or something produces a change or perturbation in the tap, laminar flow changes to a turbulent flow chaos that can be illustrated using a fluorescent liquid introduced by a dispenser located in the middle of the pipe.

Radziszewski reviwed Obeng's pipe flow analog model in the context of the fast-paced innovation environment of the twenty-first century and suggested that using some fluid mechanics relationships that also captures flow changes, an innovation metric could be defined. With this in mind, he explored the development of an innovation metric.

In this study, based on Linstone's model, we as technology practitioners developed several analog models for different moments of I\&D+I projects at the Applied Sciences and Technology Institute (ICAT, from Spanish) which is part of the National Autonomous University of México (UNAM). We present brief explanations for each model and an illustration of the model.
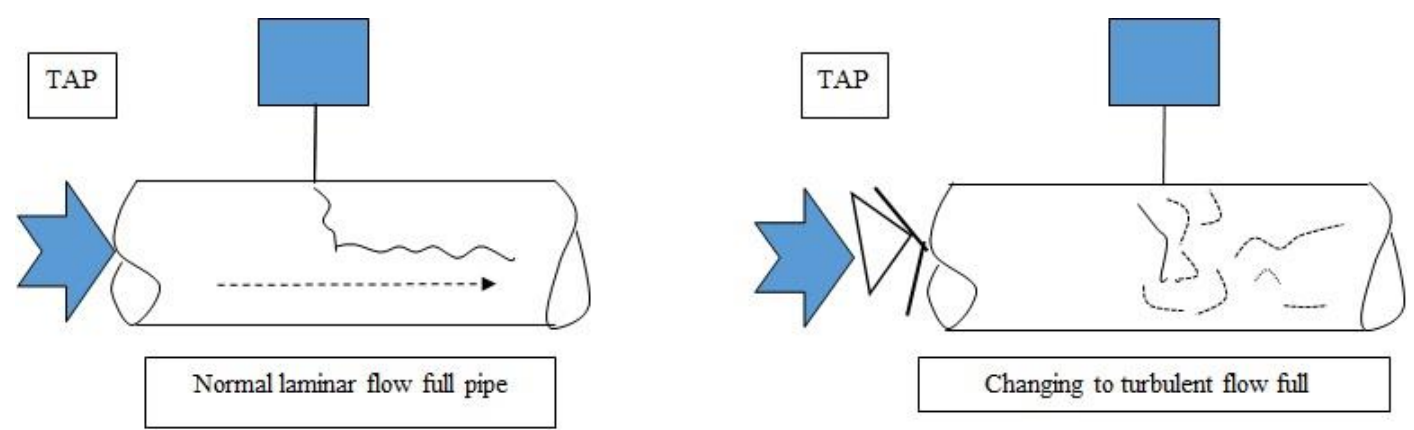

Figure 1. Obeng fluid dynamic analogy for change

Source: Redrawn from Obeng, (2012) 


\subsubsection{The Technology Products Development Model}

The hydraulic model shown in Figure 2, has a number of valves for water, connected to alternative supplies in the upper part. These represent the money needed to overcome obstacles and advance in the development of the technological prototypes.

It is evident that different obstacles are faced by universities and firms engaged in the advancement of new technology products development in a developing country. Processes usually begins when after conducting technology feasibility and market studies, a firm is convinced to develop technology as opposed to purchasing. This means, to overcome the organizational resistance $\boldsymbol{R} \boldsymbol{o l}$, a small enterprise will normally sign an agreement with a public university that will proceed with the technology development. Following this legal agreement, $\boldsymbol{R}_{J I}$ is overpassed.

When a group of academics accept the responsibility, project begins overcoming the second obstacle $R$ oz. The R\&D institution agrees on the initial specifications with the firm and develops a first concept prototype. The financing for this stage can come from either the firm's capital resources or from an external source, and in any case $\boldsymbol{R}_{\boldsymbol{F l}}$ is saved.

In the weeks and months following the bench prototype (D1), the concept prototype (D2) and sometimes the laboratory prototype (D3) are developed.

Completion of the D1 phase confirms the technical feasibility of the project and surmounts the $\boldsymbol{R}_{\boldsymbol{D} T 2}$ obstacle. Normally, when the concept prototype is approved, the firm will approve the second monetary payment overcoming the second financing resistance $\boldsymbol{R}_{\boldsymbol{F} 2}$. With this payment, the works of phase concept D2 continue.

With the approval of the concept prototype, the $\boldsymbol{R}_{\boldsymbol{D} T 3}$ obstacle is overcome. If the concept prototype is approved, the university usually receives the third monetary payment bypassing the third financing resistance $\boldsymbol{R}_{F 3}$.

In a similar fashion the development and approval of the laboratory prototype overcome resistances $\boldsymbol{R}_{\boldsymbol{D} T 3}$ y $\boldsymbol{R}_{\boldsymbol{F} 3}$ in phase D3. At this point, a technology transfer agreement is usually signed.

Following this, the economic contributions to overcome $\boldsymbol{R}_{F 5}$ and $\boldsymbol{R}_{F 6}$ could come from the government, the enterprise or from another source. With the escalation of the laboratory prototype to a pre-industrial or industrial product, $\boldsymbol{R}_{\boldsymbol{D} T S}$ and $\boldsymbol{R}_{\boldsymbol{D} T 6}$ are bypassed and only $\boldsymbol{R}_{\boldsymbol{M} I}$ that depends on the marketing team responsible and the market acceptance remains.

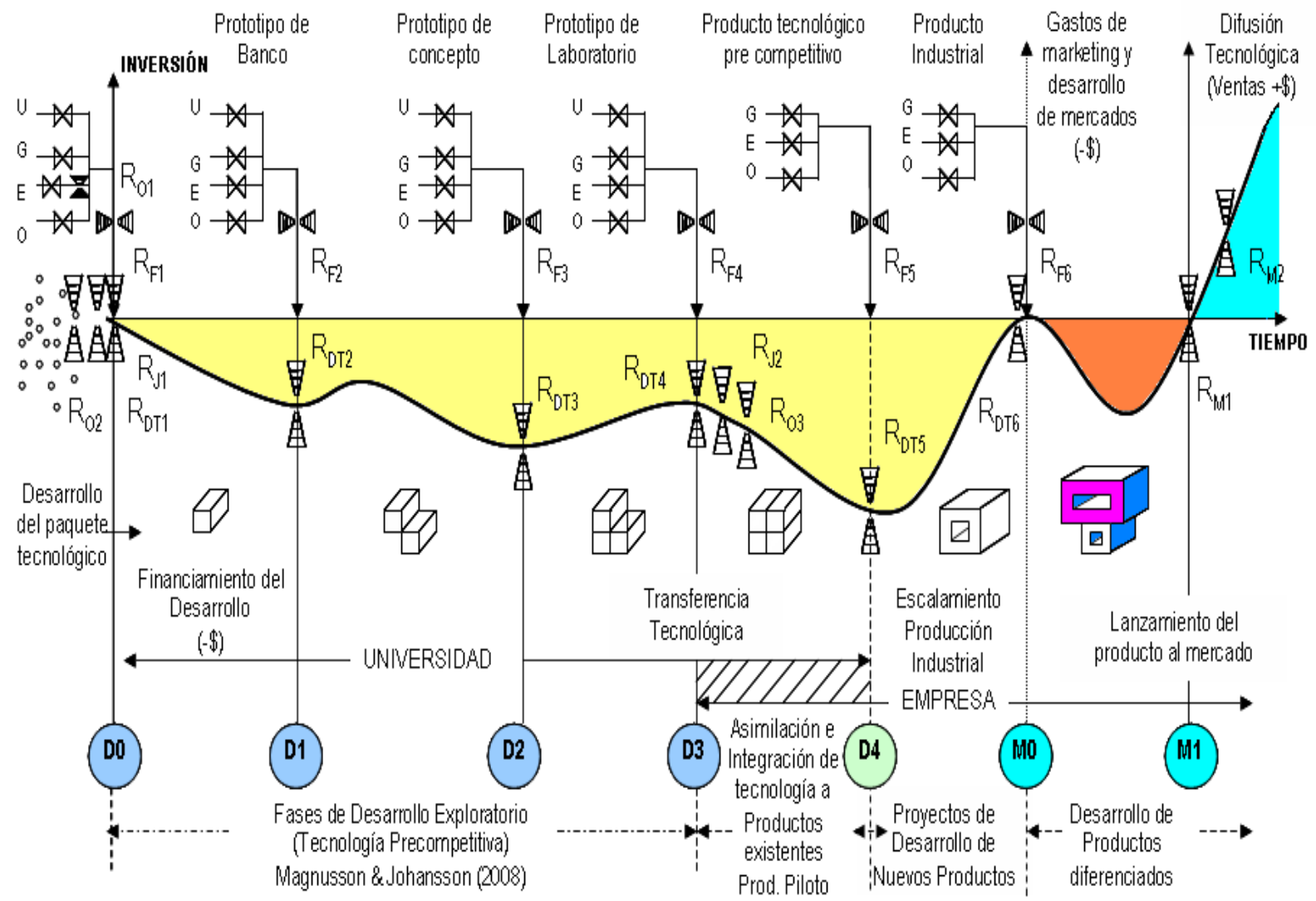

Figure 2. The technological products development process

Source: Vega-González (2009) 


\subsubsection{The Technology Valuation Model}

A basic requirement for negotiating for technology developed at universities and transferring it to a firm that will produce it and launch it into the market, diffuse in society and exploit it, is knowing the technology's commercial value. Based on the idea that all rivers are water flow currents running to the oceans, the model proposed in Figure 3 developed to determine the value of technology, takes into account that any innovation project, including the technology development, can be divided in several specific stages.

To determine the technology's value, we first need to identify where the SVP's that add value to the technology are found. Beginning at the left of Fig. 3, there are some intangible organization assets that contribute to the value of technology. The R\&D Groups, SPV 1 and the technical experts' capabilities, SPV 2, are part of the project team and are therefore indicators of the organization's tacit knowledge. The scientific knowledge SPV 3, the technology know-how SPV 4, and the existing intellectual property rights SPV 5 that were used and are still available for the project are considered explicit knowledge. SPV 6, 7 and 8 are related to the construction costs of concept, bench and laboratory prototypes. SPV 9 refers to new intellectual property rights that may be generated at the end of the project. Finally, SPV 10 shown at the upper right corner of Fig. 3, represents an indirect measurement or an assumption of the possible commercial trade of the technology. The valuation method should express the monetary value of each of the SVP's shown, and for that purpose, the analyzer must use a combination of several common methods and pragmatic price considerations (Muniesa, 2007).

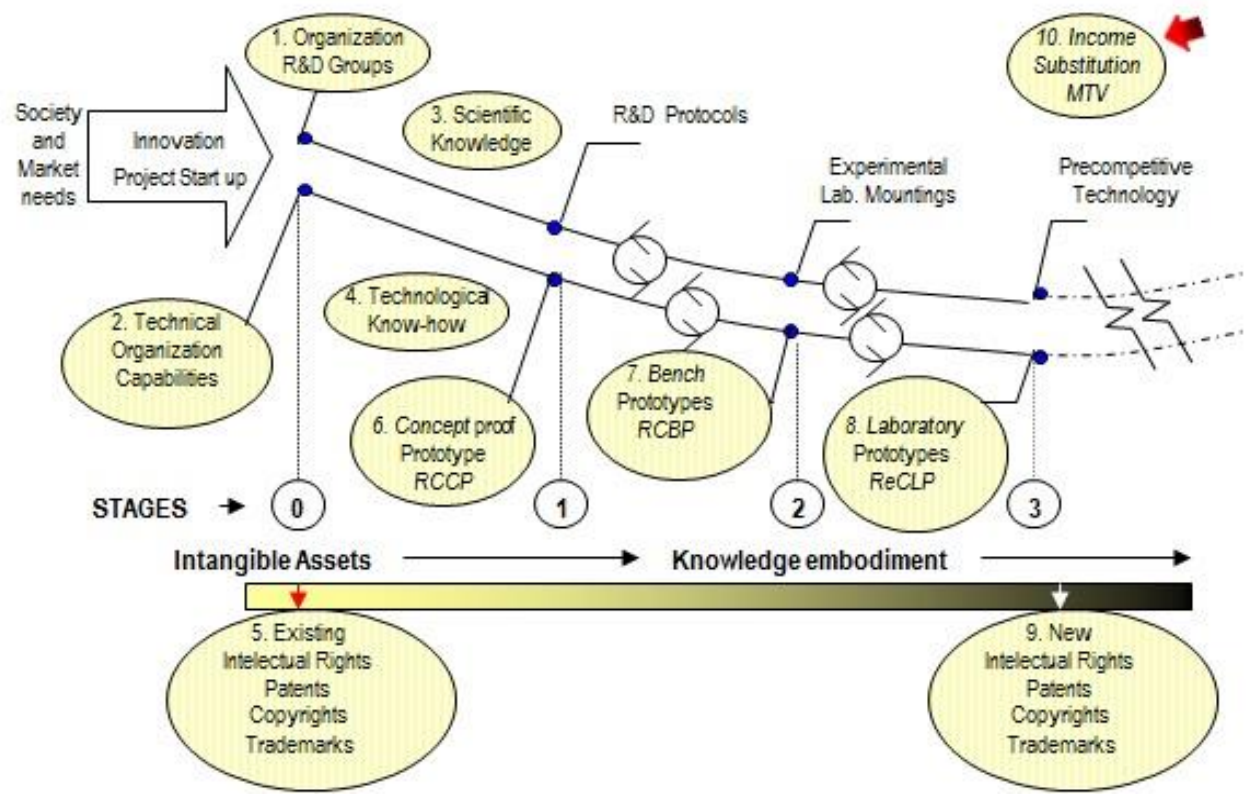

Figure 3. Specific valuating points (SVP's) identified in technology development life cycle

Source: Vega-González et al. (2010)

\subsubsection{The Simplified Systemic Model for Evaluation of Innovation Projects}

The rocket model shown in Figure 4 offers a means to perform a rapid evaluation of innovation projects. The rocket journey to innovation begins with the initial idea which fuels the motors represented by the different R\&D stages. The basic evaluation process divides the total time required for the innovation trip into five well determined stages. For quantification purposes, there is also a scale used to rate the project's advancement and performance. For quantification purposes in Figure 4, each project stage is represented by a variable $\mathrm{x}_{\mathrm{nm}}$, where $\mathrm{n}=1,2,3,4,5$ represents the stage number, and $\mathrm{m}=1,2$, represents the factors that add value along the innovation trip and are used to balance the procedure. In other words, the evaluation requires that for each stage, two different aspects must de qualified.

For example, in order for a project to obtain the maximum qualification for the variable $\mathrm{x}_{11}$, the leader and the research team must be highly recognized in addition to having the necessary infrastructure. Naturally, the evaluator must perfectly know the details of the development processes of the $\mathrm{R} \& \mathrm{D}+\mathrm{i}$ project to be evaluated. The range of values proposed for each variable is $0.25 \leq x_{i j} \leq 1.0$. Qualification will also depend on project performance

For greater ease, the maximum value for each project stage is two (2) points. In this regard the maximum qualification for the whole project is ten (10) points.

The first example of qualifying criteria is shown for the variable $\mathrm{x}_{23}$; Intellectual property, will receive 1 (one) point if 
there is at least one patent for the project technology, qualification will be 0.75 if we have utility models, 0.5 if have industrial models, and 0.25 if we have author rights. Qualifications can be founded on a mix of intellectual property certificates. The second example shown is for variable $\mathrm{x}_{41}$; production and national sales focused the problem several individuals and organizations face in an attempt to increase the speed of diffusion of the technological innovation.

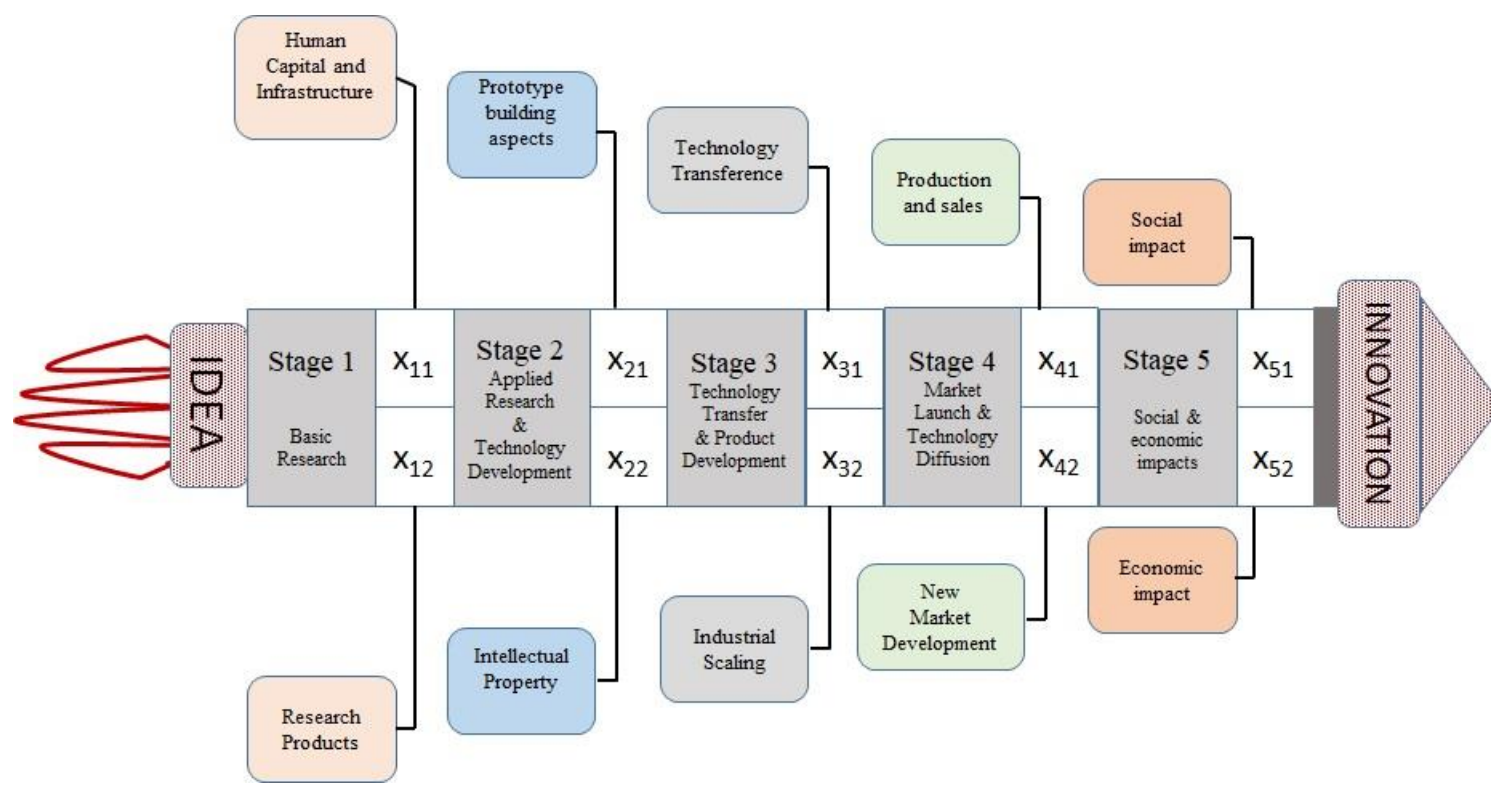

Figure 4. Stages of a systemic simple model for an innovation Project (I\&D+i)

Source Vega-González (2014)

\subsubsection{The Innovation Strings Models Based in Kondratieff Long Waves (LW's)}

Kondratieff's work in 1920 recognized that world economy is associated to LWs. (Kondratieff, 1926). Kondratieff found that although there are economic waves with different frequencies, and that the average duration for a recurring cycle is about fifty years. Furthermore, it is evident that the world economy reaches a new peak, some countries become richer, others become poorer, and the new international socio-economic makeup fosters a smooth restructuring in the global geopolitical system.

According to that, a Kondratieff Wave (KW) can be defined as a rise and fall of an economic growth mode caused by the appearance of new disruptive technology in the world markets, its diffusion, assimilation, adaptation and later crisis followed by the hard transition from an economic production mode to a new one. The oscillatory phenomenon discovered by Kondratieff is very relevant since its' study has helped to explain the economic and social behavior of the world system as it appears to be consistent over the history of several centuries.

The innovation strings model is based on the conception that flows of money are the economic energy that propitiates the $\mathrm{KW}$ result from the appearance of many inventions that produce disruptive innovations that have given rise to technological revolutions.

The model shown in Figure 5 illustrates innovation strings (K-5 and K6) drivers occurring during fourth Kondratieff LW (1930-1970). G's means invention generations; Li stands for late inventions of the previous LW innovation strings. In every new economic cycle, inventions related to previous and post LWs continue around the world. For example, mass consumption disruptive inventions continued during the time period of K-4 LW. Clearly, a new innovation string was strengthened during the K-4 LW time period, the K-6 LW drivers with applications to integral health. 


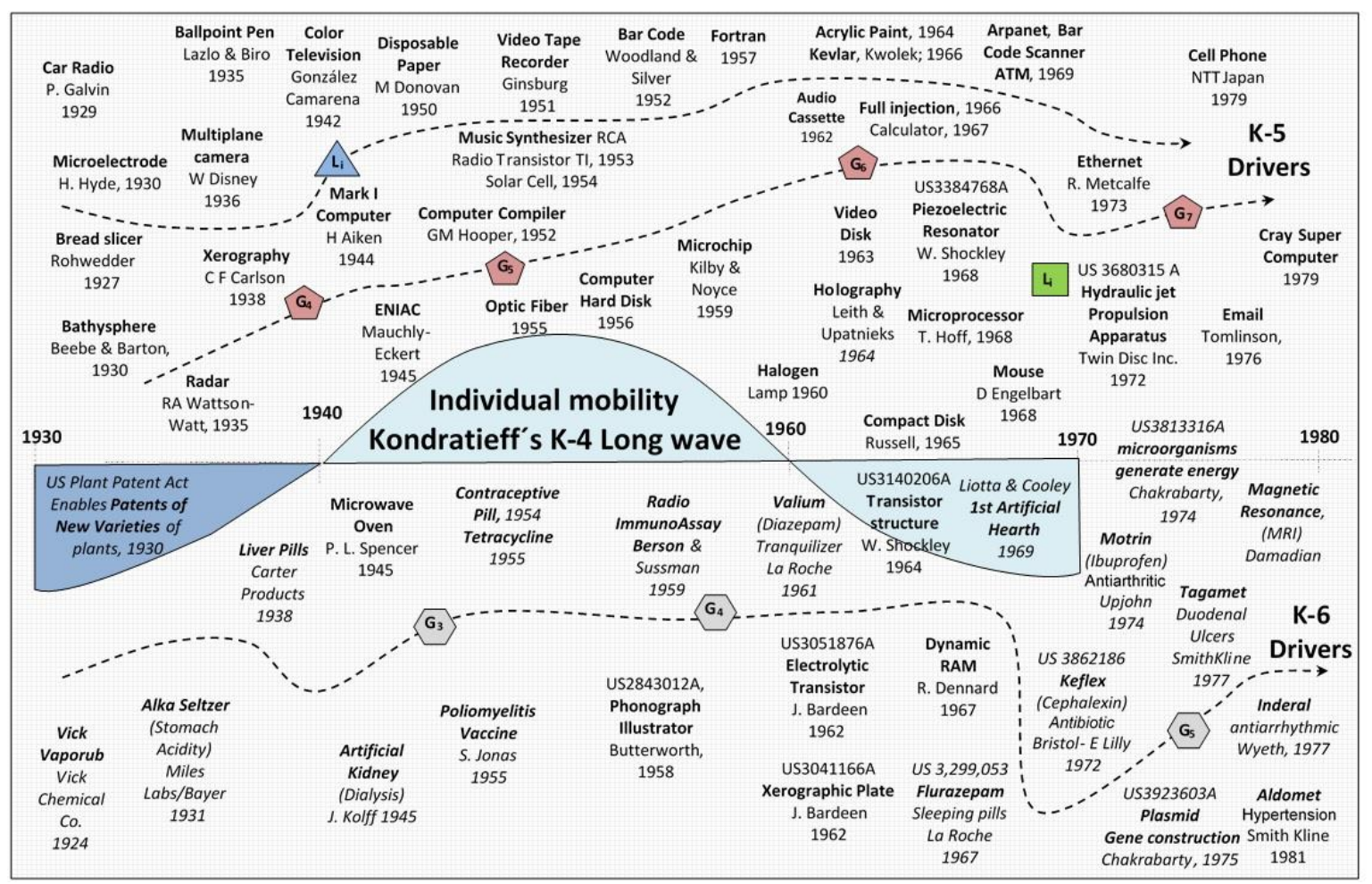

Figure 5. Innovations \& Patents of the Kondratieff's K-4 LW

Source: Vega-González (2017)

\subsubsection{The Knowledge Energy Flow Model}

In Figure 6 we see a representation of the technology development process that occurs during the R\&D+I innovation projects developed at the Institute of Applied Sciences \& Technology (ICAT) of the National Autonomous University of Mexico (UNAM), in collaboration with other public or private organizations. The central line indicates the different stages that occur in a typical project.

Stages are clearly defined by the different levels of the technology prototypes obtained in each stage. It is important to note that all the processes in each stage take a long time and require the investment of important financial resources. If all goes as planned, the funds invested will be recovered when the technological product is launched in the market and exploitation begins through sales and social technology product diffusion. The project begins when a collaboration agreement is signed between a technology developer and a counterpart who requires technology and possesses the economic resources to cover expenses and to buy the required equipment.

In this particular work, the model's idea shows that every working day, organization's individuals and academic groups learn and develop knowledge when they develop R\&D+I projects. Later, this knowledge is disseminated throughout the whole organization, like positive knowledge energy. At the bottom of Figure 6, we can see that during the journey between the different stages of a technology development project, a continuous flow of knowledge energy and recurrent learning is produced. This learning creation process can also be expanded to partner organizations who participate in the project. This phenomenon has happened to a greater or lesser degree, in different knowledge fields i.e. Health, Science and Technology Education, Environment and Energy cultivated at the ICAT. 


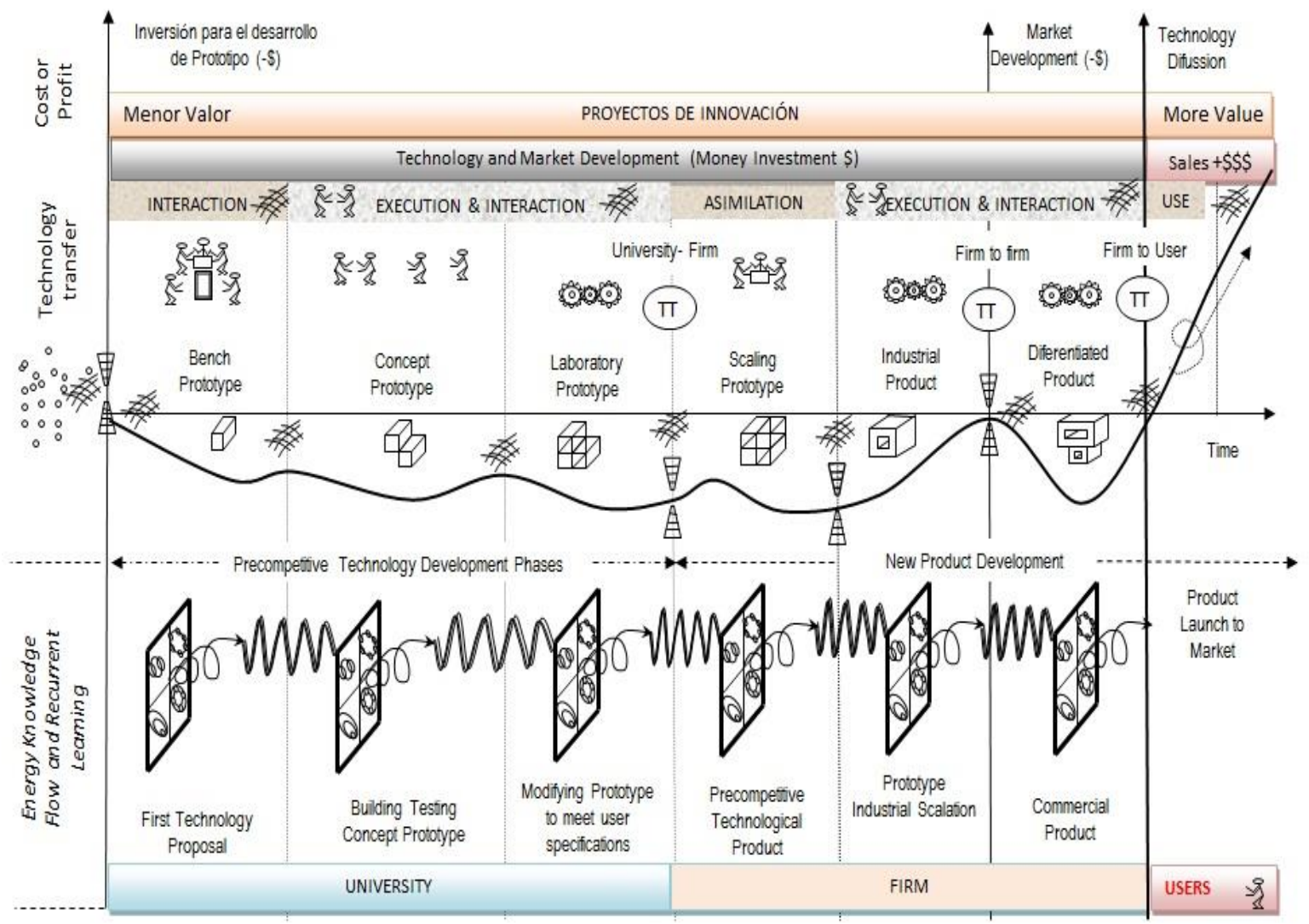

Figure 6. Knowledge Energy Flow and recurrent learning in an R\&D+I Project

Source: Vega, Zanella and Bruce (2018)

\subsubsection{The Model for Finance Impedance Matching}

The firm's parts involved in a technology transfer agreement are normally the representatives of the firm that requires technology for a new product or for improving an existing one; and a university R\&D center or Faculty that develops or owns a technology they had previously developed.

The negotiation of the terms of the technology transfer agreements is very a difficult process and often the parties involved abandon or interrupt the negotiation process. The finance impedance matching model (FIMM) presented in Figure 7, was therefore developed as a tool to reach a fair and beneficial negotiation for both parties.

The left upper part represents the R\&D stages performed by the university; the middle of the diagram represents technology transfer to the firm and the new product development developed by the firm. The right part of the diagram represents the launching of the product to market and the diffusion of the technology product expressed in estimated sales following a straight line with a slope of 500 pieces by year. 


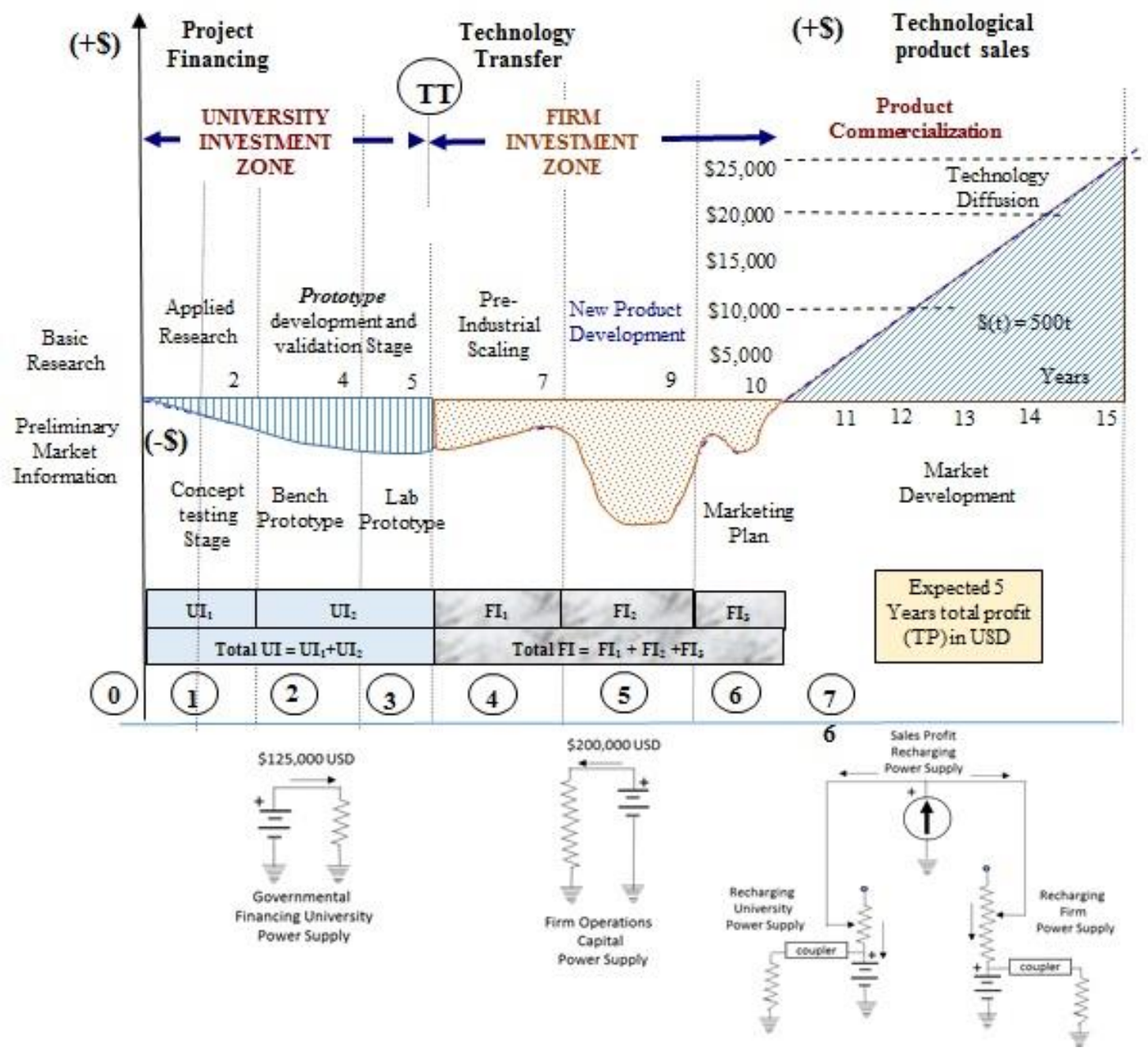

Figure 7. R\&D+I project conditions used to present the finance impedance matching methodology

Source: (Vega-González, 2020)

The basic approach is that the university will have a total investment of TUI $=\mathrm{UI}_{1}+\mathrm{UI}_{2}$ while the total investment of the firm is $\mathrm{FI}=\mathrm{FI}_{1}+\mathrm{FI}_{2}+\mathrm{FI}_{3}$. It is also possible that the technology transfer costs are equal for both the university and the Firm. Noticeably the firm will finance the marketing studies and promotional activities.

On the right, a straight line represents the expected sales of the product that will produce earnings to cover the investments done by the university and by the firm at some point will desirably cover the development costs. Furthermore, the basic idea of the model is that sales will also produce profits that must be shared by the counterparts in a proportionate to their economic investment and all their efforts. In other words, parties are not opposed but function as a team that seeks the same goals.

In the lower part of the model, there is a circuit's analogy that works as follows: (1) to make the circuit work (i.e. the innovation project) two separated voltage batteries represent the energy supplied by both the university and the firm. This energy is distributed to the resistances that represent different investments they should make to cover project costs over time. In the lower right side, there is a current power supply (PS) that represents the profits obtained from the sales of the new product; analogously, it will introduce external energy to recharge the exhausted voltage batteries. Using adequate couplers can thus help both the university and the firm to continue running technology development projects full charge; that means, with earns and profits.

The procedure to determine technology transfer terms is based on building several investment sceneries and comparing them to different sales estimations; in addition, it is necessary to consider a range of royalties and the upfront payment that the firm pays to the university until the process converges on the fairest balanced option. This balance forms the basis of the name of the model i.e. the investments made by both parts are equal and therefore matched. This is only possible when counterparts open and interchange real financial and technical information and sign confidentiality agreements in an environment of trust and compromise. 


\subsubsection{The Networking Model to Improve the Liaison Function in a Health Institution}

This is derived from chronic economic problems in the country and the austerity installed by the new government regime in the Mexican Republic, in 2018, i.e., the guidelines issued for all governmental institutions, including those of the health sector. These guidelines direct institutions to do more with less; that is, to obtain better results and greater efficiency with the same or even with fewer resources from the annual budget. To address this requirement, the liaison network model shown in Figure 8 was proposed for the National Institute of Genomic Medicine (INMEGEN).

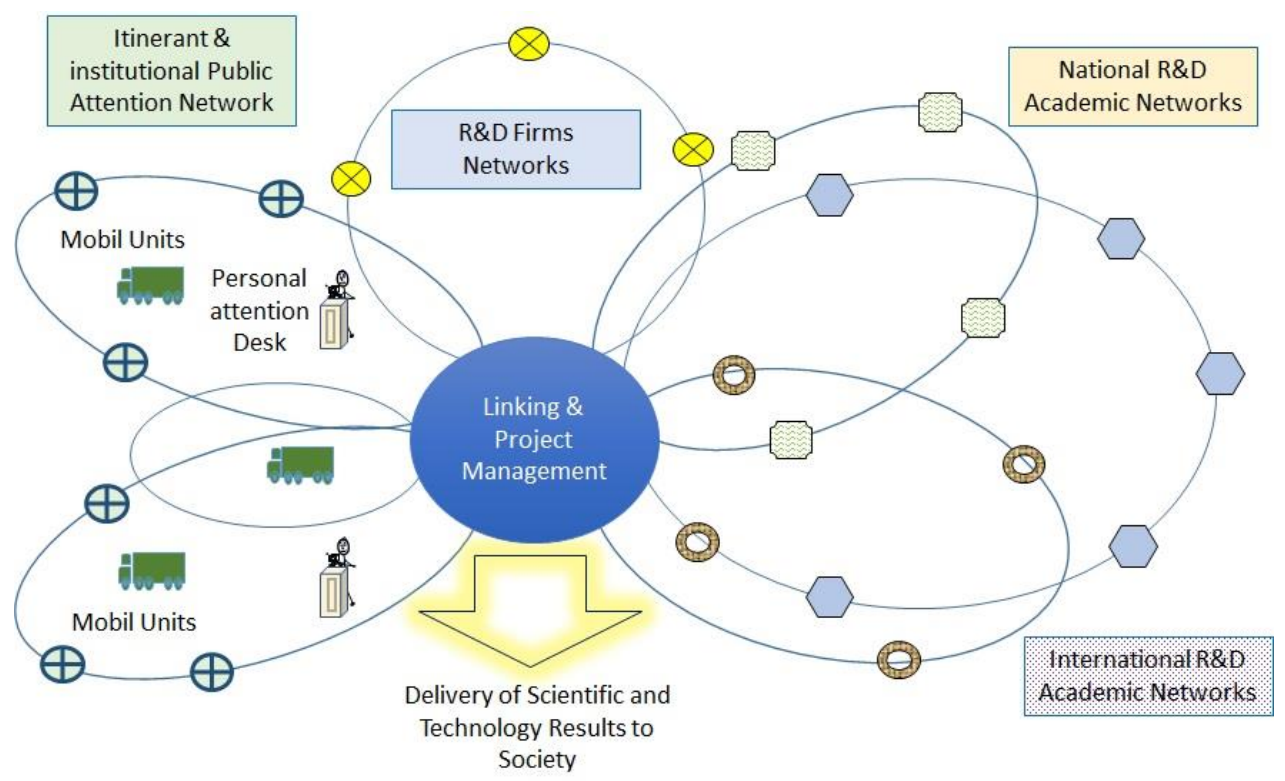

Figure 8. Liaison and project management model for a health Research Institute

Source: Vega-Salinas and Vega-González (2020)

Since the need of better liaison fundamentally requires improvement in communication media, a model of radiation patterns of antennas for broadcasting was designed.

The central idea of the model is to use computer networks to develop both national and international networks for academic research. The Institute's Liaison Directorate with the administrative authorities and under the supervision of the Institute's Research Directorate, will jointly coordinate communication with the academics or groups of academics who will act as contact nodes of the different networks that actually exist or will be formed.

Researchers who are part of the networks should also make efforts to establish and develop R\&D projects with companies and private firms, by seeking direct financing or getting it through the governmental funds of the National Council of Science and Technology (CONACYT), the Secretariat of Science and Technology of Mexico City (SECITI) or Foundations, among other avenues.

Beyond research excellence, the following are ranked among the fundamental premises that ought to be fulfilled by the projects that will be developed by the R\&D Networks: in the medium term, achievement of applicable and proven knowledge results that are accessible to all society members and markets. The problem lies not only in the development of internal capacities and access to the latest information and knowledge, but also in the development of new forms of network management to achieve agile communication, efficient coordination and good performance of projects.

\subsubsection{The Rotational Mechanical System as a Liaison and Innovation Model}

A type of physical system in which energy is particularly "visual" and its vibrations feel strongly, are the rotational mechanical systems. 


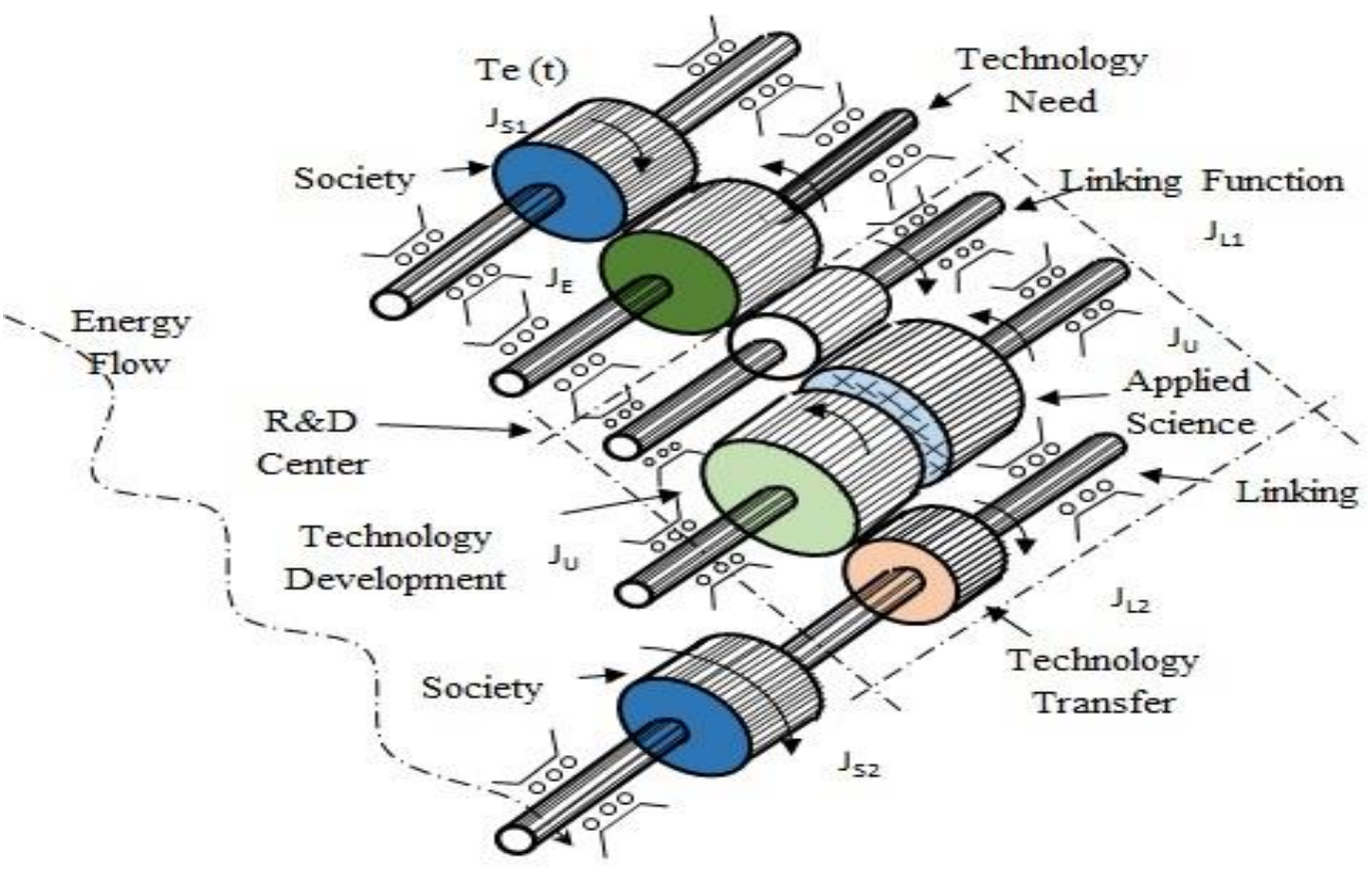

Figure 9. Rotational mechanic model for liaison and technology transfer

The objective of the rotational mechanic model shown in Figure 9, is to show how the liaison function is like a crazy gear that does not increase or reduce the angular velocity, nor the power transmission of the systems mounted in the different rotational axis, it permits the coupling between the different rotational systems and the energy flow through the entire system, producing useful mechanical work.

In Figure 9, the first cylindrical inertia $\left(\mathrm{J}_{\mathrm{S} 1}\right)$ represents any society organization or sector that receives the initial energy impulse represented as a pair force $\mathrm{T}_{\mathrm{e}}(\mathrm{t})$. This may be seen as a technology requested by some societal sector. Enterprises $\left(\mathrm{J}_{\mathrm{E}}\right)$ are the rotational units in contact with the different society sectors that require technology solutions. The inertia $\mathrm{J}_{\mathrm{L} 1}$ represents the liaison function that puts the requirements of $\mathrm{J}_{\mathrm{E}}$ in contact with the capabilities to develop applied science and technology at the universities $\left(\mathrm{J}_{\mathrm{U}}\right)$. The liaison function $\mathrm{J}_{\mathrm{L} 2}$ once again intervenes with other capabilities to negotiate the terms of the technology transfer agreements so that technological products can possibly finally reach another society sector $\mathrm{J}_{\mathrm{S} 2}$.

\section{Conclusion}

There are three notable characteristics of $R \& D+I$ projects performed in Mexican public universities. The first is the multidisciplinary nature of the scientists, engineers, designers and technical people directly involved in these projects, as well as the professional accounting, administrative and technical staff required to support these processes. Furthermore, lawyers are required to run all the legal procedures for the technical and support institutional staff. Moreover, the constitution of the institutional authorities and other stakeholders is also multidisciplinary. The second notable feature is the prolonged duration required for these projects which runs contrary to the technological life cycle. The third notable characteristic is the funds required to carry out $\mathrm{R}+\mathrm{D}+\mathrm{I}$ projects. Therefore, to make these projects more efficient, a common and simple language that allows the different actors and stakeholders to understand phenomena and processes that occur throughout the development of the projects is essential. Regardless of the analyst's profession, analog models based on what happens in common physical systems turn, are facilitate the understanding the phenomenology of technology management during the different stages of the projects cycle. This is because analog models serve as a graphic language that can be easily understood by all regardless of their profession or specialty.

To develop analog models, heuristic experience gained through handling many of such models and learning to identify the problems that affect them, along with their alternative solutions is required. In that regard, heuristics is seen as the pragmatic art of inventing with the intention of seeking strategies, methods, criteria that allow problem-solving through creativity and divergent or lateral thinking. 
In that regard, the objective proposed for this work was to present several pragmatic analog models based in physical systems that reflect the characteristics of the management of technology of R\&D+I projects that are externally financed, developed at the Institute of Applied Sciences and Technology (ICAT, from the Spanish) of the National Autonomous University of Mexico from 2000 to 2020.

To address this, we presented eight models related to different activities of $R \& D+I$ projects technology management. The models specifically presented were: (a) the technological products development process, (b) a technology valuation model using specific valuating points (SVP's, (c) a simplified systemic model for evaluation of innovation projects, (d) an innovation strings model based in Kondratieff Long Waves, (e) a knowledge energy flow model, (f) a model for finance impedance matching, (g) a networking model to improve the liaison function in a health institution, and finally (h) a rotational mechanical system that functions as a Liaison and Innovation model.

The above analog models were derived from practical technology management work done on approximately 300 projects. We are fully aware that the variables of technological management that occurred in them were continuous and did not permit the collection of discrete data for holistic analysis of phenomena in detail with a wide angle lens. Therefore, they did not offer significant statistical information. However, the models presented have shown that there is an alternative method that could be used to obtain meaningful pragmatic knowledge based on experience that could easily be shared with other interested practitioners.

\section{References}

Ackoff, R. L. (1974). Redesigning the Future: A Systems Approach to Societal Problems. Wiley, New York, 1974.

Aduríz-Bravo, A. (2012). Algunas características clave de los modelos científicos relevantes para la educación química. Educación Química. Áreas Emergentes de la Educación en Química. Publicación en línea por la Universidad Nacional Autónoma de México, pp. 1-9. ISSNE 1870-8404. https://doi.org/10.1016/S0187-893X(17)30151-9

Aguilera, H. R. M. (2013). Identidad y diferenciación entre Método y Metodología. Estudios Políticos, Facultad de Ciencias Políticas y Sociales, UNAM. núm. 28, 81-103. ISSN: 0185-1616. https://doi.org/10.1016/S01851616(13)71440-9

Bagnato, V. S., \& Rodrigues, V. (2006). Anâlogo mecânico para condutividade elétrica dos metais: Efeito da temperatura. Revista Brasileira de Ensino de Física, 28(1), 35-39. https://doi.org/10.1590/S1806-11172006000100005

Belmonte, J. L., \& Sierra, M. (2011). Modelos intuitivos del infinito y patrones de evolución nivelar. Revista Latinoamericana de investigación en matemática educativa, 14(2), 139-171. Available at http://www.scielo.org.mx/pdf/relime/v14n2/v14n2a2.pdf

Bettis, R., \& Prahalad, C. K. (1995). The Dominant Logic: Retrospective and Extension. Strategic Management Journal, 16, 5-14. https://doi.org/10.1002/smj.4250160104

Chamizo, J. A. (2006). Los modelos de la química, Educ. quím., 17(4), 476-482. https://doi.org/10.22201/fq.18708404e.2006.4.66030

Coll, R. K., France, B., \& Taylor, I. (2005). El papel de los Modelos Analógicos en la Educación en Ciencias: Implicaciones desde la Investigación.Revista Eureka Enseñanza y Divulgación de la Ciencia. Available at www.apac-eureka.org/revista/volumen3/Numero3_1_/rese\%F1a_2006_1.pdf

https://doi.org/10.25267/Rev_Eureka_ensen_divulg_cienc.2006.v3.i1.12

Emre, B., \& Önner, M. A. (2014). An Exploratory Study on the Development and Application of Integrated Information Technology Management Model. International Journal of Innovation and Technology Management, 11(3), 1-30. World Scientific Publishing Company. https://doi.org/10.1142/S0219877014500187

Fernández, J., Jiménez, T., \& González, B. (2003). Las Analogías como Modelo y como Recurso en la Enseñanza de las Ciencias. (In line document). Available at http://www.grupoblascabrera.org/didactica7pdf/

Godoy, L. A. (2002). Éxitos y problemas de las analogías en la enseñanza de la mecánica. Journal of Science Education, 3(1), 11-15. SciTech Premium Collection.

Katz, D., \& Kahn, R. (1978). The Social Psychology of Organizations. Wiley: New York. 
Liévano, M. F., \& Villada, O. J. G. (2013). Un modelo de dinámica de sistemas para la administración de inventarios. Revista Soluciones de Postgrado EIA, Año VI, 6(11), 121-135. ISSN: 2811-3854. http:/dx.doi.org/10.14508/rsdp.2013.6.11.121-135

Linstone, H. (1984). Multiple perspectives for Decision Making, bridging the gap between analysis and action, pp. 422. North-Holland: Elsevier Science Pub. Co.

Mejía, Q. E., \& Escobar, M. H. (2012). Caracterización de procesos cognitivos de memoria, lenguaje y pensamiento, en estudiantes con bajo y alto rendimiento académico. Diversitas: Perspectivas en Psicología, 8(1), 123-138. Universidad Santo Tomás, Bogotá, Colombia. ISSN: 1794-9998. https://doi.org/10.15332/s17949998.2012.0001.08

Muniesa, F. (2007). Market technology and the pragmatics of prices. Economy and Society, 36(3), 377-395. https://doi.org/10.1080/03085140701428340

Palmer, B. (2009). Noted cognitive scientist asserts that analogy is (almost) the whole enchilada. Stanford Report. Retrieved from https://news.stanford.edu/news/2006/february22/hofstadter-021506.html

Peralta, E. (2016). General systems theory applied to management models. AGLALA, 7(1), 122-146. ISNN: 2215-7360.

Radziszewski, P. (2020). Exploring the development of an innovation metric - from hypothesis to initial use. Journal of Innovation and Entrepreneurship, 9(10), 1-29. https://doi.org/10.1186/s13731-020-00118-4

Rengifo, V. V. M., Fariña de Lander, Y., \& Cabrera de Reyes, E. (2009). Modelo analógico para enseñar biotecnología: Una experiencia en el aula. Paradígma, 30(2), 201-203. Available at http://ve.scielo.org/scielo.php?script=sci_arttext\&pid=S1011-22512009000200013\&lng=es\&tlng=es

Rolleri, J. L. (2013). Qué son los modelos físicos? Valenciana Revista de Filosofia y Letras, 6(11), 271-289. ISSN: 20072538. https://doi.org/10.15174/rv.v0i11.23

Sánchez, P. G., \& Luengas, C. L. A. (2011). Aplicación del modelo RC en sistemas biológicos (mecánica ventilatoria). Facultad de Ingeniería UNIMINUTO. Inventum, 10, 16-23. ISSN: 1909-2520. https://doi.org/10.26620/uniminuto.inventum.6.10.2011.16-23

Saritas, O., \& Oner, M. A. (2004). Systemic analysis of UK foresight results Joint application of integrated management model and roadmapping. Technological Forecasting \& Social Change, 71, 27-65 https://doi.org/10.1016/S00401625(03)00067-2

Siles, I. (2007). Cibernética y sociedad de la información: el retorno de un sueño eterno. Signo y Pensamiento 50, XXVI, 85-99. ISSN: 0120-4823.

Terrazas, P. R. A. (2009). Modelo de Gestión Financiera para una organización. Universidad Católica Boliviana San Pablo Cochabamba, Bolivia. Perspectivas, núm. 23, 55-72. Retrieved from http://www.redalyc.org/articulo.oa?id=425942159005

Vega-González, L. R. (2009). El proceso de desarrollo de productos tecnológicos entre las universidades y la MIPYMES Mexicanas: una carrera de obstáculos. Journal of Technology Management and Innovation, 4(4), 120-129. ISSN: 0718-2724. https://doi.org/10.4067/S0718-27242009000400010

Vega-González, L. R., Qureshi, N., Kolokoltsev, O. V., Ortega-Martínez, R., \& Saniger, B. J. M. (2010). Technology valuation of a scanning probe microscope developed at a university in a developing country. Technovation. 30, 533539. https://doi.org/10.1016/j.technovation.2010.06.001

Vega-González, L. R. (2014). Desarrollo de una metodología rápida para evaluación de proyectos de innovación $(I \& D+i)$. Caso de una universidad pública mexicana, XVIII Congreso Internacional de Investigación en Ciencias Administrativas (ACACIA); Capítulo 11 Ingeniería y Gestión de Sistemas ALTEC 2014, Universidad Autónoma de Baja California, Tijuana Baja California, México., 22 al 26 abril 2013. ISBN 978-0-9911261-6-3; 17 pp.

Vega-González. (2017). Using patents and innovation strings to anticipate the next Kondratieff long waves. Int. J. Technology Intelligence and Planning, 11(3), 212-229. https://doi.org/10.1504/IJTIP.2017.10006430

Vega-González, L. R., Zanella, R., \& Bruce, N. (2018). Knowledge Energy, Recurrent Learning and the Transformation of an R\&D Institution in a Mexican Public University. Case Studies in Business and Management, 5(2), 41-58. ISSN: 2333-3324. https://doi.org/10.5296/csbm.v5i2.13628 
Vega-González, L. R. (2020). Finance Impedance Matching Methodology (FIMM) for enhancing university-firm technology transfer. Research in Business and Management, 8(1), 11-32. ISSN: 2330-8362. https://doi.org/10.5296/rbm.v7i1.15488

Vega-González, L. R., \& Vega-Salinas, R. M. (2020). Plan para desarrollar una red de Vinculación y Gestión para una Institución Mexicana de I\&D en Salud. Revista CEA, 6(12), 89-111. Instituto Tecnológico Metropolitano - ITM; Medellín, Colombia. ISSN-p 2390-0725, ISSN-e 2422-3182. https://doi.org/10.22430/24223182.1504

Wiener, N. (1949). Cybernetics or Control and Communication in the Animal and the Machine. New York, the Technology Press.

Zamorano, R., Gibss, H., \& Viau, J. (2006). Modelización analógica en la enseñanza de circuitos de corriente continua. Journal of Science Education, 7(1), 30-33. SciTech Premium Collection.

Zapata, R. G., \& Canet, G. M. T. (2009). La cognición del individuo: reflexiones sobre sus procesos e influencia en la organización. Espacio Abierto Cuaderno Venezolano de Sociología, 18(2), 235-256. ISSN: 1315-0006. http://www.redalyc.org/articulo.oa?id=12211826003

\section{Copyrights}

Copyright for this article is retained by the author(s), with first publication rights granted to the journal.

This is an open-access article distributed under the terms and conditions of the Creative Commons Attribution license which permits unrestricted use, distribution, and reproduction in any medium, provided the original work is properly cited. 